\title{
Prevalence of Measles Amongst Children (0 - 5 Years) Attending Imo State University Teaching Hospital (Imsuth), Orlu
}

\author{
Nwagwu SAJ, Obiajuru IOC*, Ibebuike JI and Vincent CC \\ Department of Nursing Science, Imo State University, Orlu Campus, Nigeria \\ *Corresponding Author: Obiajuru IOC, Department of Nursing Science, Imo State \\ University, Orlu Campus, Nigeria.
}

Received: January 18, 2022

Published: February 18, 2022

(C) All rights are reserved by Obiajuru IOC., et al.

\begin{abstract}
The study was carried out to determine the prevalence of measles amongst children in Imo State University Teaching Hospital (IMSUTH) Orlu. The aim of the study is to provide data on the prevalence of measles among children (0-5years) in IMSUTH, to determine the most affected age group, to identify the most prevalent complication of measles and to find out the month with the highest incidence rate. It exposes the prevalence of measles in Imo State University Teaching Hospital Orlu, assesses the magnitude and severity of the disease and provides a template that will help relate to mothers where this condition is prevalent. A descriptive epidemiological study on the prevalence of measles among children (0-5) attending IMSUTH 2014 to 2018. 14,712 children reported to the hospital with different ailments within this period, out of this population, 419 children had measles which was used as the sample size for the study. Computer check list, data complication form and calculator were used as instruments for this study. Data collected was analyzed using tables, figures, and graphs. Out of 14,712 cases, 419 (2.8\%) presented with measles in the five years study. The prevalence of measles was highest between January -December 2014 and least between January-December 2018. The gender prevalence of measles showed measles occurring more in males (49.7\%) than females (50.3\%). It occurred in children between the ages of 1-2years (30.8\%) and the peak month incidence was seen in January (18.4\%), May (66\%), February (11.2\%) and December (11\%). Some patients developed a form of complications of which bronchopneumonia was the highest (75\%), while some who were immunized still presented with the disease (27.5\%). In conclusion, measles complications can be reduced by immunization. Vitamin A also helps susceptible children prevent complications.
\end{abstract}

Keywords: Measles; Nigeria; Children

\section{Introduction}

Measles is an acute and highly contagious disease which is characterized by fever, rashes, coryza, conjunctivitis and generalized maculopapular, erythematous rash. It has a high morbidity, mortality and chase fatality rate of about 5\% 1[]. A larger proportion occurs in the tropical and developing countries. The disease affects mainly the younger age groups and is the cause of about 1.5 million death per year in different countries of the world. This is attributed to poor nutritional standard, secondary bacterial infections, poor environmental conditions, inadequate medical care and lack of immunization etc.
This disease spread by droplet infection or through person to person contact. These facts have been implicated in the increased number of people infected in an over populated area where most individuals are not immunized. Also, there can be a history of the disease in a previously immunized individual and this can be due to primary immunization failure. The infection is rarely found in infants less than 6 months old (who are exclusively breast feed) because they possess an increased number of maternal antibodies. Because measles is one of the leading cause of death among children in the tropics, it's devastating relationship with the health of the Nigerian child cannot be over emphasized (Onyiriuka 2011). 
Worldwide, among the burden of vaccine preventable disease, measles ranks first with $8 \%$ disease burden [2]. In developing countries measles is a major cause of childhood morbidity and mortality due to underling malnutrition and over-crowding [3]. A rapid increase in measles immunization coverage is known to produce changes in the epidemiology of the disease, indicating that strategies for control of measles may also require constant review (Onyiriuka, 2011).

Measles is known to affect both immunized and non-immunized children, although the prognosis is better in the former than the later. This study seeks to determine the prevalence of measles among children attending Imo State University Teaching Hospital Orlu. The study will measure the demographic data of children who attended IMSUTH Orlu, from January 2014 to December 2018 and presented with this disease. This will be used to determine the prevalence of measles among children at IMSUTH Orlu.

Among the burden of vaccine - preventable disease worldwide, measles ranks first with $8 \%$ disease burden [2]. A rapid increase in measles immunization coverage is known to produce changes in the epidemiology of the disease. Measles is a highly infectious disease, endemic in developing courtiers with a peek transmission from October to March, annually. The fatality rate of measles to developing countries stands at about 3 to $5 \%$, and could be as high as $10 \%$ during epidemics. It is one of the leading causes of death among children even though a safe and cost effective anti-measles vaccine is available. Merriam-Webster defined measles as: an acute contagious disease, caused by a mobilivirus (species of measles virus) and marked by an eruption of red spots, fever and signs of inflammation of the respiratory tract (coryza, cough). Measles, a highly contagious viral disease remains an important cause of death among young children.

\section{Objectives of the Study}

Measles, being a childhood disease is seen mainly in the preschool aged children and most times, due to its presentation (fever and rash) is misdiagnosed by parent as a mere rash either due to drug or skin hypersensitivity reactions. As a result of this wrong diagnosis or over sight, complications can occur. The specific objectives of the study are:

- $\quad$ To determine prevalence of measles per year (2014 to 2018) in children at IMSUTH Orlu.
- To determine the decline in the incidence of measles from 2014 - 2018

- $\quad$ To determine the Gender - related Prevalence of measles in IMSUTH 2014 to 2018

- $\quad$ To determine the Age - related Prevalence of measles at IMSUTH Orlu 2014 to 2018

- $\quad$ To determine the Prevalence of measles infection in immunized and non- immunized children in IMSUTH Orlu, 2014 to 2018

- To determine the Monthly Distribution of measles at IMSUTH Orlu, 2014 to 2018

- To determine the degree of measles complications in IMSUTH, Orlu.

\section{Materials and Methods}

\section{Study area}

This Study was carried out at Imo State University Teaching Hospital, Orlu metropolis. Orlu is a major city in Imo State, SouthEastern Nigeria. The hospital is a tertiary health institution and enjoys a high level of referral cases within the State. Its peadiatric department is made up of children's out patient, children's emergency and children's ward. The city is well known for commerce and industry and hence has problems common in cities, such as over-crowding indiscriminate sewage disposal and dirty environment $[4,5]$. These conditions make children susceptible to diseases and infections. The climate condition is basically rainy and dry seasons lasting from April to October and from November to March respectively.

Imo State is large in human population and suffers from overcrowding and poor sanitation. Refuse and household wastes are indiscriminately dumped by road sides, market sides and other public places [6]. There are all the factors that promote measles outbreak.

\section{Population of study}

The study population is all children ( 0 to of 5 years) attending paediatric Clinic of the hospital during the study period

\section{Sample size}

The sample size is $2.8 \%$ of 14,712 (sick children in the peadiatric department) which is 419 children. 
Method of data collection

Relevant data needed were obtained from available existing hospital records. These include patient files and folders at the medical record department. The records in the children emergency unit were also collected and analyzed.

\section{Method of data analysis}

These data collected were analyzed using descriptive statistics which includes graphical, tabular and numerical analyses as in Philips [7], Obiajuru and Ozumba, 2017. Summaries aid inferential statistics that tests the relationship among variables.

\section{Ethical consideration}

Ethical permit was obtained from the Ethical Committee, Imo State University Teaching Hospital, Orlu.

\section{Results}

Prevalence of measles

A total number of 14,712 paediatric cases was reported at IMSUTH. Out of this number, 419 children representing $2.8 \%$ were diagnosed with measles, while $97.2 \%$ presented with other diseases. The prevalence of measles at Imo State University Teaching Hospital Orlu, within the study period is summarized in table 1 and figure 1.

\begin{tabular}{|c|c|c|c|c|c|c|}
\hline \multirow{2}{*}{ Year } & \multicolumn{3}{|c|}{$\begin{array}{c}\text { Number of children with } \\
\text { measles }\end{array}$} & \multicolumn{3}{|c|}{$\begin{array}{c}\text { Total number of } \\
\text { peadiatic cases }\end{array}$} \\
\cline { 2 - 7 } & Male & Female & Total & Male & Female & Total \\
\hline \multirow{2}{*}{2014} & 83 & 68 & 151 & 1910 & 1655 & 3577 \\
\cline { 2 - 7 } & $55.4 \%$ & $45 \%$ & $4.2 \%$ & $53.4 \%$ & $46.5 \%$ & \\
\hline \multirow{2}{*}{2015} & 63 & 51 & 114 & 1827 & 1780 & 3607 \\
\cline { 2 - 7 } & 63 & $4.8 \%$ & $3.2 \%$ & $50.7 \%$ & $49.5 \%$ & \\
\hline \multirow{2}{*}{2016} & 33 & 27 & 60 & 1319 & 1296 & 2615 \\
\cline { 2 - 7 } & $55 \%$ & $45 \%$ & $14.3 \%$ & $50.4 \%$ & $49.6 \%$ & \\
\hline \multirow{2}{*}{2017} & 14 & 44 & 58 & 1222 & 898 & 212 \\
\cline { 2 - 7 } & $24.3 \%$ & $75.8 \%$ & $13.8 \%$ & $57.6 \%$ & $42.4 \%$ & \\
\hline \multirow{2}{*}{2018} & 15 & 21 & 36 & 1271 & 1522 & 2793 \\
\cline { 2 - 7 } & $41.7 \%$ & $58.3 \%$ & $1.3 \%$ & $47.8 \%$ & $54.5 \%$ & \\
\hline \multirow{2}{*}{ Total } & 208 & 211 & 419 & 7777 & 6923 & 14712 \\
\cline { 2 - 7 } & $49.7 \%$ & $50.3 \%$ & $2.8 \%$ & $52.8 \%$ & $47.1 \%$ & \\
\hline
\end{tabular}

Table 1: Prevalence of measles in IMSUT Orlu, 2014 to 2018.

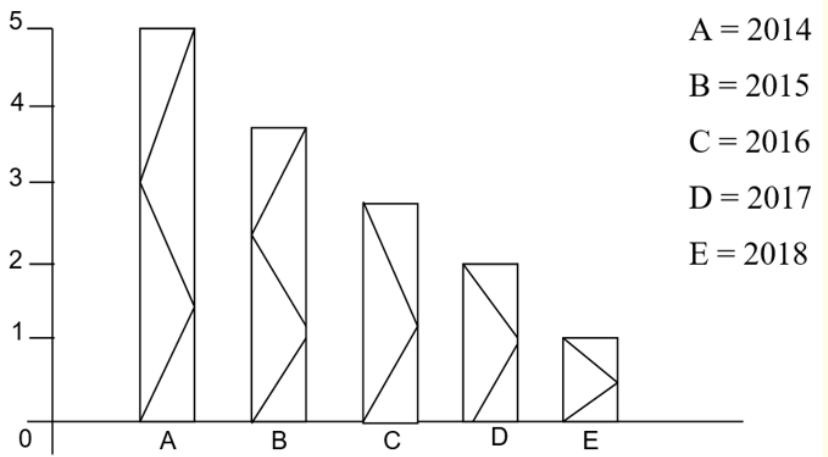

Figure 1: A bar chart showing the yearly prevalence of measles in IMSUTH.

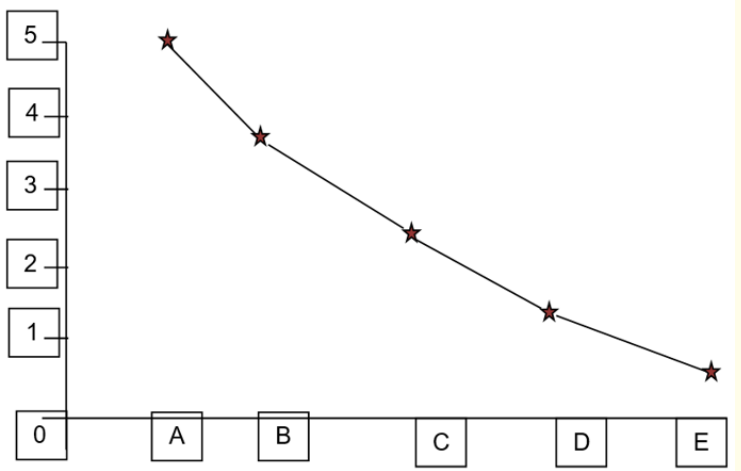

Figure 2: Shows a decline in the incidence of measles from 2014 - 2018 study years. The highest incidence was recorded in 2014 study year.

Gender prevalence

Gender - related prevalence of measles at IMSUTH Orlu, 2014 to 2018 is summarized in figure 3.

\begin{tabular}{|l|c|c|c|}
\hline Year of study & Males & Females & Total \\
\hline 2014 & $83(54.9 \%)$ & $68(45.1 \%)$ & 151 \\
\hline 2015 & $63(55.3 \%)$ & $51(44.7 \%)$ & 114 \\
\hline 2016 & $33(55 \%)$ & $27(45 \%)$ & 70 \\
\hline 2017 & $14(24.3 \%)$ & $44(75.8 \%)$ & 58 \\
\hline 2018 & $15(41.7 \%)$ & $21(58.3 \%)$ & 36 \\
\hline Total & $208(49.7 \%)$ & $\begin{array}{c}211 \\
(50.3 \%)\end{array}$ & 419 \\
\hline
\end{tabular}

Table 2 


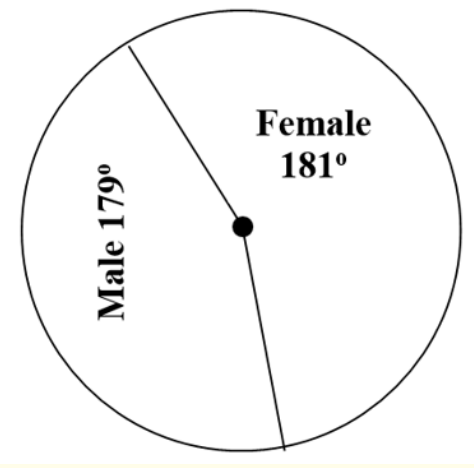

Figure 3: A pie chart showing the gender - related prevalence of measles $($ male $=1790$, female $=1810)$.

\begin{tabular}{|l|c|c|c|c|c|}
\hline Year & $<\mathbf{1}$ year & $\mathbf{1 - 2}$ years & $\mathbf{3 - 4}$ years & $\mathbf{> 4}$ years & Total \\
\hline 2014 & $\begin{array}{c}35 \\
(23.2 \%)\end{array}$ & $\begin{array}{c}44 \\
(29.1 \%)\end{array}$ & $\begin{array}{c}37 \\
(24.5 \%)\end{array}$ & $\begin{array}{c}35 \\
(23.2 \%)\end{array}$ & 151 \\
\hline 2015 & $\begin{array}{c}20 \\
(17.5 \%)\end{array}$ & $\begin{array}{c}36 \\
(31.6 \%)\end{array}$ & $\begin{array}{c}30 \\
(26.3 \%)\end{array}$ & $\begin{array}{c}26 \\
(24.6 \%)\end{array}$ & 114 \\
\hline 2016 & $14(20 \%)$ & $\begin{array}{c}24 \\
(34.3 \%)\end{array}$ & $18(25 \%)$ & $\begin{array}{c}14 \\
(20 \%)\end{array}$ & 70 \\
\hline 2017 & $\begin{array}{c}10 \\
(20.8 \%)\end{array}$ & $\begin{array}{c}15 \\
(31.3 \%)\end{array}$ & $12(25 \%)$ & $\begin{array}{c}11 \\
(22.9 \%)\end{array}$ & 48 \\
\hline 2018 & $\begin{array}{c}11 \\
(30.6 \%)\end{array}$ & $\begin{array}{c}10 \\
(27.8 \%)\end{array}$ & $8(22.2 \%)$ & $\begin{array}{c}7 \\
(19.4 \%)\end{array}$ & 36 \\
\hline Total & $\begin{array}{c}90 \\
(21.2 \%)\end{array}$ & $\begin{array}{c}129 \\
(30.8 \%)\end{array}$ & $105(25 \%)$ & $\begin{array}{c}95 \\
(22.7 \%)\end{array}$ & 419 \\
\hline
\end{tabular}

Table 3: Age - related Prevalence of measles at IMSUTH Orlu 2014 to 2018.

Key: $<1$ year $=76.3^{\circ} ; 1-2$ years $=110.8^{\circ} ; 3-4$ years $=90^{\circ} ;<4$ years $81.7^{\circ}$.

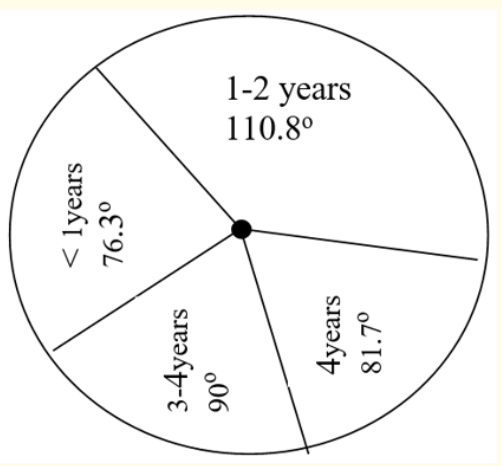

Figure 4: A pie chart showing the age distribution of measles cases in IMSUTH.
From the data above, it can be deduced that the ages of 1-2 years are the most susceptible the measles.

Immunized/Non-immunized patients

Most patients still contracted measles even after being immunized against the disease, non-immunized patients also came up with measles within the 5years of study.

\begin{tabular}{|l|c|c|}
\hline Study year & Immunized patients & $\begin{array}{c}\text { Non-immunized } \\
\text { patients }\end{array}$ \\
\hline 2014 & $32(21.2 \%)$ & $119(78.8 \%)$ \\
\hline 2015 & $28(24.6 \%)$ & $86(75.4 \%)$ \\
\hline 2016 & $25(35.7 \%)$ & $45(64.3 \%)$ \\
\hline 2017 & $18(37.5 \%)$ & $30(62.5 \%)$ \\
\hline 2018 & $12(33.3 \%)$ & $24(66.7 \%)$ \\
\hline Total & $115(27 \%)$ & $304(73 \%)$ \\
\hline
\end{tabular}

Table 4: Prevalence of measles infection in immunized and non-immunized children in IMSUTH Orlu, 2014 to 2018.

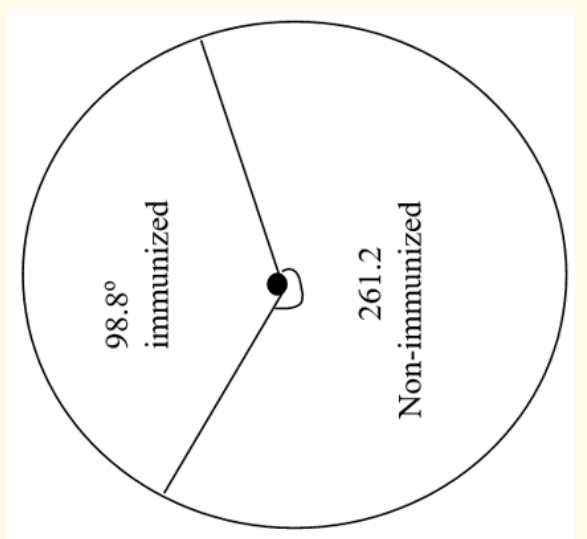

Figure 5: A pie chart showing the prevalence of measles amongst immunized and non-immunized patients at IMSUTH Orlu, 2014 to 2018 (Immunized $=98.80$, Non-immunized $=261.20$ ) .

\section{Monthly distribution of measles at IMSUTH Orlu, 2014 to 2018}

Measles readily occurs in every month of the year with peak occurrences during the festive and dry periods of the year. These months include from December though may can be seen in the table below. 


\begin{tabular}{|l|c|c|}
\hline Month & Number of patients & Percentage \\
\hline January & 77 & $18.4 \%$ \\
\hline February & 47 & $11.2 \%$ \\
\hline March & 44 & $10.5 \%$ \\
\hline April & 32 & $82.7 \%$ \\
\hline May & 66 & $15.8 \%$ \\
\hline June & 23 & $5.5 \%$ \\
\hline July & 9 & $2.2 \%$ \\
\hline August & 22 & $5.3 \%$ \\
\hline September & 33 & $7.9 \%$ \\
\hline October & 8 & $1.9 \%$ \\
\hline November & 12 & $12.9 \%$ \\
\hline December & 46 & $11 \%$ \\
\hline
\end{tabular}

\begin{tabular}{|l|c|c|c|}
\hline Year of study & Complicated & In complicated & Total \\
\hline 2014 & $39(26 \%)$ & $112(74 \%)$ & 151 \\
\hline 2015 & $30(26.3 \%)$ & $84(73.6 \%)$ & 114 \\
\hline 2016 & $20(28.6 \%)$ & $50(71.4 \%)$ & 70 \\
\hline 2017 & $12(25 \%)$ & $36(75 \%)$ & 48 \\
\hline 2018 & $7(19.4 \%)$ & $29(80 \%)$ & 36 \\
\hline Total & $108(25.8 \%)$ & $311(74.2 \%$ & 419 \\
\hline
\end{tabular}

Table 6: Annual Distribution of complicated and non complicated cases of measles in IMSUTH Orlu, 2014 to $2018(\mathrm{~N}=419)$.

Table 5: The percentage occurrence of measles in months within the 5 years of study.

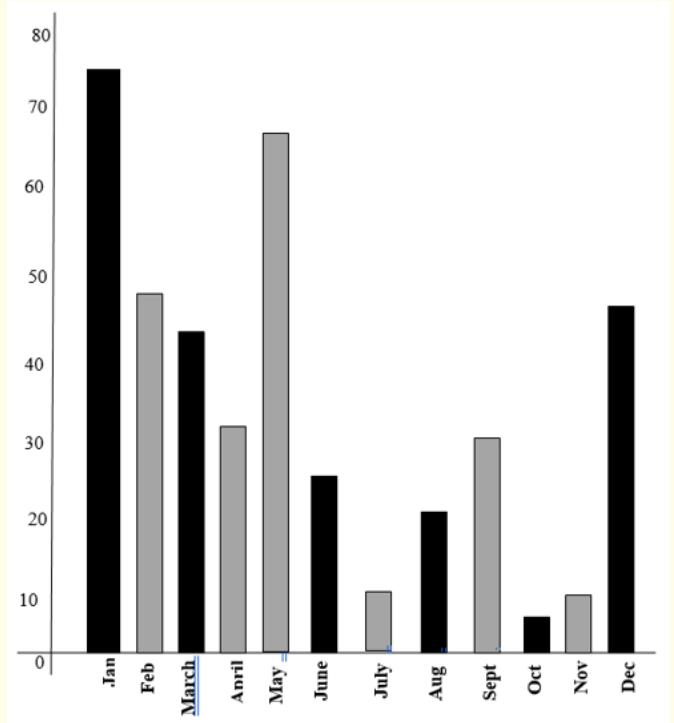

Figure 6: A bar graph showing total number of patient's per month in IMSUTH.

The rise in the number of measles during these months can be attributed to various factors such as the weather condition and the festivities during that same period of time.

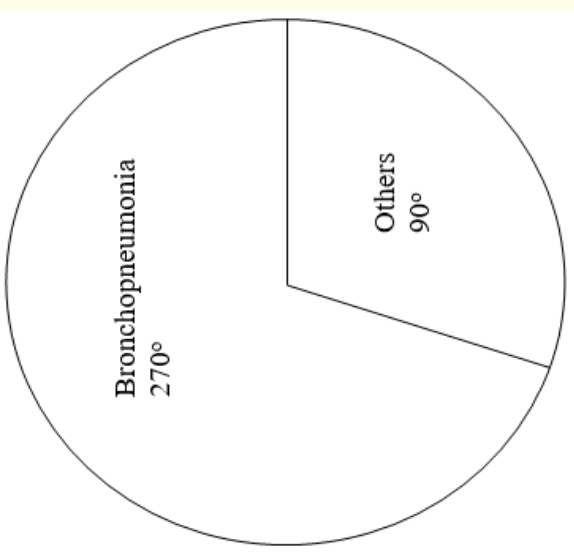

Figure 7: A pie chart showing the percentage of complicated and non-complicated cases in IMSUTH.

108 patients had complicated measles in the years under study, of this number, 81 (75\%) had bronchopneumonia as the major complication; while 27 had other complications.

\begin{tabular}{|l|c|c|c|}
\hline Year & Bronchopneumonia & Other & Total \\
\hline 2014 & $29(74.4 \%)$ & $10(25.6 \%)$ & 39 \\
\hline 2015 & $23(76.7 \%)$ & $7(23.3 \%)$ & 30 \\
\hline 2016 & $15(75 \%)$ & $5(25 \%)$ & 20 \\
\hline 2017 & $9(81.8 \%)$ & $3(18.2 \%)$ & 11 \\
\hline 2018 & $5(71.4 \%)$ & $2(28.6 \%)$ & 7 \\
\hline TOTAL & $81(75 \%)$ & $27(15 \%)$ & 108 \\
\hline
\end{tabular}

Table 7: Complication from measles infection $(\mathrm{N}=108)$.

\section{Complications associated with measles}

Measles can have a lot of deficiency complications ranging from headache to pregnancy problems. 


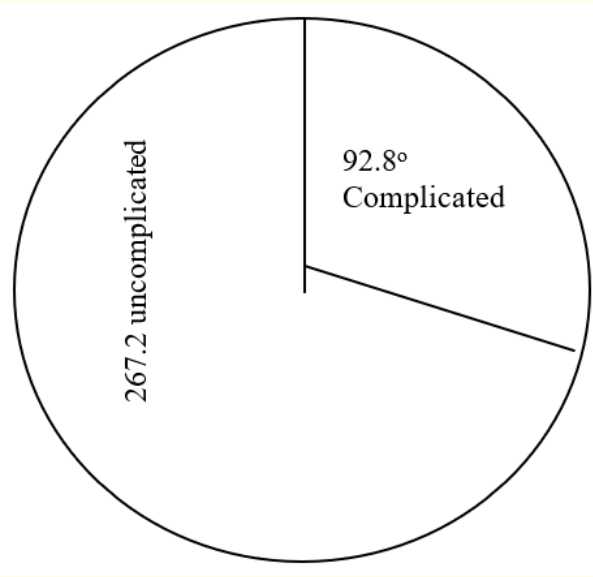

Figure 8: A pie chart showing the percentage c.

Note: Others include Otitis media and encephalitis.

Demographic - related prevalence of measles

Industrialization and demographic transition can generate instability in human population that can affect the transmission and persistence of infectious disease. Majority of the patients $311(74.2 \%)$ were resident in rural areas with 108 (25.8\%) residing in urban areas. This might be as a result of poor health infrastructure in the rural areas.

\section{Discussion of Findings and Conclusion}

Measles can be acute and highly contagious mainly characterized by fever, rashes, cough and coryza. It can be contacted through droplet infection or through person to person contact accounting for immense number of people infected in an over populated area where most individuals are not immunized. The findings of the present study showed that there was high prevalence of measles at IMSUTH Orlu, 2014 to 2018. The prevalence decreased progressively as the year's progress. This can be attributed to the increase in awareness and consequent modification of immunization strategies [8-12].

Majority of the children, about $94.0 \%$ were resident in the rural area with only $6.1 \%$ ) in the urban area. There have been no established reason for this but this could be due to the fact that parents in the rural area have poor health seeking behavior and health facilities.

The findings of this study showed that many children, that presented with measles, were children below the age of 1 year $30.8 \%$, between the ages of 1 to 2 years, 25\% and those aged 3 to 4 years $30.8 \%$. and $13.4 \%$ were children above 4 years. Similar figures were observed by Onyiriuka in 2011 where $47.8 \%$ were children between 1 to 2 years and same was reportedt by Duru 2014 .

The study showed higher prevalence of infection among females than males. However, there was no significant difference $(p$ $<0.05$ ) in the prevalence of infection between females and males. It appears that measles affect both gender indiscriminately in any given population. This finding did not agree with Reuter, (2018) who stated that boys are more prone to the infection than girls. According to him, this may stem from some fundamental vulnerability of boys.

Immunized and non- immunized patients:

Immunization plays a great role in the contraction and subsequent complication of measles. The study showed that more unimmunized children were infected than immunized children. Previous studies (Duru., et al. 2014, Ibrahim and Omoghere, 1998) observed this. About $73 \%$ of the patients in the present study were not immunized in 2011, this was similar to that observed by Duru in 2014 and Omoigber in 1998 who reported $81.2 \%$ and $83.6 \%$ respectively.

The present study showed that measles outbreak occurred throughout the year with peak occurrences between December and May, hissing highest at the month of May. This period coincides with the dry period when hot dry and dense weather aid movement of droplets. This agrees with previous studies elsewhere in Nigeria, (Ojeawo and Bello 200, Ogunmekan., et al. 2007, Onyiruka 2011).

Measles come with a variety of complication ranging from encephalitis to broncho - pneumonia. From the present study 25.8\% patients had complications with broncho - pneumonia accounting for $75 \%$ of the complications. This was also observed by Duru., et al. in Bayelsa State (Duru., et al. 2014) and also Merenu in 2016 (Merenu., et al. 2016).

Measles is an acute and highly contagious disease with a high rate fatality of $5 \%$. It has a prevalence ratio of 2.8 per 100 cases and it has declined as the years went by. It was seen more in children between the ages of 1 to 2 years with peak incidence in January, May and December. It occurred more in non- immunized children 
than the immunized ones. Majority were uncomplicated while others presented with complications of which broncho - pneumonia was marked.

\section{Contribution to knowledge}

This study has contributed immensely to advance knowledge of infectious diseases especially, measles in South Eastern Nigeria and Nigeria generally. Specifically,

- It will act as a source of information to health officials seeking to reduce the morbidity rate of measles and infectious disease among children.

- It will aid nurses especially those in pediatrics clinics and wards to understand the severity of measles.

- It will be a good reference for mothers to understand the signs /symptoms of measles and also the importance of vaccination

- It will act as a source of literature to research students and / scholars working on measles and related studies.

- The information gathered and published will be used by the government and non-governmental organizations working in Orlu and Nigeria in developing viable possible policies and measures to reduce the impact of the disease.

\section{Bibliography}

1. Obionu CN. "Primary Health care for Developing Countries". $2^{\text {nd }}$ edition. Enugu - Ezu books ltd (2012).

2. Durbey AP and Chaudhury J. "Textbook of padiatrics $4^{\text {th }}$ edition”. New Delhi: Jaypee Brothers Medical publishers lt (2013).

3. Levin MJ and Weinberg A. Measles (rubiola) L Hay Ww jnr. Levin m.J., Sondheimer J.M., Deterning Rubiola (ed) $20^{\text {th }}$ edition. New York: Mc Graw Hill (2011).

4. Obiajuru I O C and Ozumba U C. "Laboratory Methods for Medical Microbiology and Parasitology". Lifeway Amalgamations (Revised Edition). Owerri Nigeria (2017): 169.

5. Obiajuru I O C., et al. "Assessment of Glycosuria and Bacterial Infections Amongst Prolonged - Healing Orthopaedic Wound Patients in Hospitals Within Imo State South Eastern Nigeria". American Journal of Laboratory Medicine 3 (2017): 34-40.

6. Ikpeama C A., et al. "The Impact of Refuse Disposal Dump Sites on the Spread of Intestinal Helminthiasis in Owerri Metropolis, Imo State, South Eastern Nigeria". International Journal of Clinical Chemistry and Laboratory Medicine (IJCCLM) 2.2 (2016): 13-18.
7. Philip L 0. "Bayelsian Statistics for Social Scientists". Whitefriar Press. London (2002): 215.

8. Levine MI. "Jolly's disease of children $9^{\text {th }}$ edition". Toronto: Sauders Elsevier (2011).

9. Chika O., et al. "A 5 years review of childhood measles at the Niger Delta University Teaching Hospital, Bayelsa State, Nigeria". Journal of Medicine and Medical Sciences 5.4 (2014): 78-86.

10. Dunham W. Measles outbreak hits 127 people in 5 States, Leutirs, Retroviral 2008-07-10 (2008).

11. Merenu I A. Childhood measles in a South Eastern State University Teaching Hospital (2010).

12. Ojuawo A and Bello M. "Measles in Illorin". Nigerian Journal Medical 9 (2000): 101-103.

\section{Assets from publication with us}

- Prompt Acknowledgement after receiving the article

- Thorough Double blinded peer review

- Rapid Publication

- Issue of Publication Certificate

- High visibility of your Published work

Website: www.actascientific.com/

Submit Article: www.actascientific.com/submission.php Email us: editor@actascientific.com

Contact us: +919182824667 